\title{
The younger disabled unit at Fazakerley Hospital
}

\author{
T B BENSON, E WILLIAMS
}

British Medical fournal, 1979, 2, 369-371

\section{Summary and conclusions}

The activities of a new younger disabled unit reflect the changing pattern of care now being provided for severely physically disabled young people. A co-ordinated team approach to their rehabilitation has enabled all but a few of the severely disabled to continue living at home. This represents a considerable saving on the cost of hospital-based care and has afforded them the best opportunity for developing their lives to the full and enjoying a satisfactory life in the community.

\section{Introduction}

It is now over 20 years since the Ministry of Health first seriously considered the problems of the severely physically handicapped young adult. Many had become long-term residents in unsuitable hospital accommodation and therefore regional hospital boards were initially asked to consider providing more appropriate facilities for their care. No early changes followed this request, but it became evident that both the size of the problem and the best method of dealing with it were unknown. In 1966, therefore, the DHSS commissioned a pilot study to examine the needs of and facilities for the younger chronic sick in hospital. A comprehensive national inquiry later showed that more than 4223 physically disabled young adults aged from 16 to 59 were receiving long-term care in non-psychiatric

\section{Fazakerley Hospital, Liverpool L9 7AL, UK}

T B BENSON, MB, MRCP, consultant physician in rheumatology and rehabilitation

E WILLIAMS, MB, MRCP, consultant physician in rheumatology and rehabilitation hospitals administered by the National Health Service. About half of them were accommodated in long-stay geriatric wards and were thus both mentally and socially deprived by their environment. This was most unsatisfactory, and clearly there was an obvious and urgent need for more suitable accommodation. Several charitable bodies, notably the Cheshire Foundation, had earlier recognised this need and adopted a more enlightened approach to the problems of providing appropriate residential care.

Nevertheless, further provision was obviously necessary, and in 1968 a Ministry directive ${ }^{1}$ recommended setting up residential units on district hospital sites. These were to be called young chronic sick units, and a provision of 25 beds per 500000 population was suggested. Since the disabled were expected to remain in these units indefinitely, regional hospital boards were advised to achieve a more informal and homely atmosphere than was normal in a district hospital.

The younger disabled unit at Fazakerley Hospital was designed to comply with these recommendations, but during the period before its commissioning, attitudes towards the care of the young physically disabled had begun to change. The passive support of the hospital that had encouraged dependence on others was being replaced by a desire to promote independence. This change of emphasis led to the development and exploitation of residual abilities rather than the passive acceptance of disability. The importance was recognised of achieving the maximum independence of the disabled to enable them to have the optimum opportunity to improve the quality of their lives while preserving family and community ties.

\section{Facilities and stafing}

The unit is a one-storey building pleasantly sited within the 180-acre campus of Fazakerley General Hospital and can accommodate 26 patients in five four-bedded wards and six single rooms. It also houses a communal area together with smaller and quieter areas 
such as a patients' library and sitting room. Occupational therapy and physiotherapy services are available within the unit, but the present facilities are inadequate and need expansion.

Two consultant physicians in rheumatology and rehabilitation with supporting staff provide medical cover. The consultants also co-ordinate the activities of the rehabilitation team (a trained nursing staff of 10, 11 nursing auxiliaries, a senior physiotherapist and a senior occupational therapist, each helped by a basic grade therapist and a senior social worker). All these work full time but others, such as the disablement resettlement officer, DHSS technical officer, speech therapist, and psychologist, attend on a sessional basis.

\section{Catchment population and policy}

The unit's catchment population is about three million people. This represents the population dependent for health care provision on the Mersey Regional Health Authority, the Isle of Man Health Services Board, and the Clwyd and Gwynedd areas of the Welsh Regional Health Authority. It aims at providing assessment, treatment, and support services for the physically disabled adults aged from 16 to 55 years to encourage them to improve the quality of their lives within the community. It specifically does not provide a service for those with a disabling degree of psychiatric illness.

Patients are referred normally by other medical practitioners to one of the two consultants who have clinical responsibility within the unit. All are first assessed on a domiciliary or outpatient basis to avoid inappropriate admission, and then other members of the unit's staff undertake their own evaluation of the patient's problems. Regular case conferences are held to discuss the patient's problems with members of the rehabilitation team, which ensures the co-ordinated planning of the most appropriate pattern of care for individual patients.

One-third of the available beds are needed for patients whose assessment, management, or treatment may be expected to take less than one month. A parent, spouse, or other relative will occasionally lodge in the unit with such a patient when instruction in nursing procedures or the use of equipment is necessary. One-third of the beds are used for patients needing intensive rehabilitation over a period of up to three months. During this time these patients spend gradually increasing periods at home, and as ability and confidence return the degree of support provided by the unit is progressively withdrawn. The remaining third of the bed complement is for individuals who in the opinion of the consultants and unit staff need the continuous nursing and medical and laboratory support of a district hospital.

Patient reassessment is continued either by the unit's staff visiting the disabled in their homes or by reattendance as outpatients. Shortterm readmission is occasionally provided to relieve a supporting family, but whenever possible appropriate community-based holiday or hostel accommodation is arranged.

\section{Inpatient care $\mathbf{1 9 7 5 - 8}$}

For many years long-term care had been provided for the young severely disabled adult at Fazakerley Hospital, and at the beginning of 197512 patients were being cared for on a long-term basis. Four were resettled at home without great difficulty, two have since died, and one who had been resident for eight years was transferred at the age of 67 to a geriatric unit near to his previous home.

Five patients (table I) remained for whom there was no satisfactory alternative but to continue in long-term care. These patients had lived in the unit for an average of seven years (2-18 years), and both they and their families regarded it as their permanent home.

In the last quarter of 1975 further admissions to the unit were delayed until the new policies outlined earlier could begin to operate

TABLE I-Details of long-stay residents in 1975

\begin{tabular}{|c|c|c|c|c|c|}
\hline Diagnosis & & & & Age & $\begin{array}{c}\text { Length of stay } \\
(\mathrm{yr})\end{array}$ \\
\hline $\begin{array}{l}\text { Traumatic tetraplegia C5-C6 ... } \\
\text { Multiple sclerosis (tetraplegia).. } \\
\text { Anterior poliomyelitis (tetraplegia) } \\
\text { Traumatic tetraplegia C3-C4 } \ldots \\
\text { Traumatic tetraplegia C3-C4 .. }\end{array}$ & $\begin{array}{l}\cdots \\
\cdots \\
\cdots \\
\cdots\end{array}$ & $\begin{array}{l}\cdots \\
\cdots \\
\cdots \\
\cdots\end{array}$ & $\begin{array}{l}\cdots \\
\cdots \\
\cdots \\
\cdots\end{array}$ & $\begin{array}{l}29 \\
50 \\
47 \\
23 \\
56\end{array}$ & $\begin{array}{r}10 \\
2 \\
18 \\
3 \\
4\end{array}$ \\
\hline
\end{tabular}

under the responsibility of a consultant with a special interest in rehabilitation. Acceptance of young severely disabled patients started again at the beginning of 1976, although facilities and staff did not increase until 1977. Since then the number of patients assessed and admitted has progressively increased (table II).

Almost all of the patients admitted have exhibited severe physical disability and have been very heavily dependent on others. (All have represented category IV or $\mathrm{V}$ on the Rankin scale. $\left.{ }^{2}\right)$ Nevertheless, a balance of admissions and discharges has been maintained. The duration of stay has been reduced, with most patients being discharged within one month (table III). This has probably resulted from limiting admission to the age group 16-55 years (table IV), for there is some evidence that increased length of stay is more common with a higher age on admission:

Throughout the three years sequelae of previous neurological disease have necessitated most $(93 \%)$ admissions of patients. Although a very wide range of disease has been observed, those admitted have been placed in six broad groups according to the course of their illness and the pattern of rehabilitation required (table $\mathrm{V}$ ).

TABLE II-Number of admissions and discharges during 1975-8

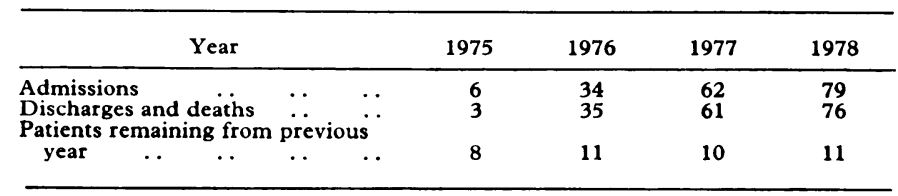

TABLE III-Duration of stay in unit

\begin{tabular}{lllcccc}
\hline & & & 1976 & 1977 & 1978 \\
\hline Short stay (less than one month) & $\ldots$ & $\ldots$ & 20 & 40 & 50 \\
Medium stay (1-3 months) & $\cdots$ & $\ldots$ & $\ldots$ & 8 & 10 & 11 \\
Long stay (over 3 months) & $\cdots$ & $\ldots$ & $\ldots$ & 9 & 9 & 10 \\
\hline
\end{tabular}

TABLE IV-Average age of patients in relation to length of stay

\begin{tabular}{|c|c|c|c|c|c|}
\hline & & & 1976 & 1977 & 1978 \\
\hline $\begin{array}{l}\text { Short stay (less than } 1 \text { month) } \\
\text { Medium stay }(1-3 \text { months) } \\
\text { Long stay (over } 3 \text { months) }\end{array}$ & $\begin{array}{l}\cdots \\
\cdots\end{array}$ & $\begin{array}{l}\cdots \\
\cdots\end{array}$ & $\begin{array}{l}50 \\
41 \\
51\end{array}$ & $\begin{array}{l}36 \\
45 \\
51\end{array}$ & $\begin{array}{l}38 \\
43 \\
47\end{array}$ \\
\hline
\end{tabular}

TABLE V-Major disease groups of patients needing admission 1976-8

\begin{tabular}{llcrrr}
\hline & & 1976 & 1977 & 1978 & Total \\
\hline $\begin{array}{l}\text { Rheumatic diseases } \\
\text { Hemiplegia, (cerebrovascular }\end{array}$ & $\ldots$ & 2 & 4 & 7 & $13(7 \%)$ \\
$\begin{array}{l}\text { disease, or tumour) } \\
\text { Paraplegia or tetraplegia, spinal }\end{array}$ & $\ldots$ & 9 & 20 & 23 & $52(30 \%)$ \\
$\begin{array}{l}\text { cord injury or disease } \\
\text { Multiple sclerosis .. }\end{array}$ & $\ldots$ & 5 & 18 & 18 & $41(23 \%)$ \\
$\begin{array}{l}\text { Progressive neuromuscular } \\
\text { diseases . }\end{array}$ & $\ldots$ & 11 & 9 & 14 & $34(20 \%)$ \\
$\begin{array}{l}\text { Miscellaneous disability group } \\
\text {. }\end{array}$ & $\ldots$ & 2 & 4 & 9 & $15(9 \%)$ \\
\end{tabular}

So far as possible patient admission is electively controlled so as to maintain an even work load on the unit's staff. Those severely disabled by multiple sclerosis, for example, represent a considerable demand on nurses and occupational therapists, whereas those who have sustained a stroke tend to require proportionately more of the physiotherapist's time. The rehabilitation team works most effectively when all of its members are equally and fully concerned with the unit's patients.

\section{Outpatient attendances for assessment and treatment}

With the opening of the purpose-built unit in November 1976, a greatly improved outpatient service became possible (table VI). 
TABLE VI-Outpatient attendances during 1975-8

\begin{tabular}{|c|c|c|c|c|c|}
\hline & & 1975 & 1976 & 1977 & 1978 \\
\hline $\begin{array}{l}\text { New patient referrals } \\
\text { Total outpatient attendances }\end{array}$ & $\begin{array}{l}\cdots \\
\cdots\end{array}$ & $\begin{array}{l}23 \\
28\end{array}$ & $\begin{array}{l}67 \\
95\end{array}$ & $\begin{array}{l}116 \\
754\end{array}$ & $\begin{array}{r}81 \\
542\end{array}$ \\
\hline $\begin{array}{l}\text { Ratio of new referrals to total } \\
\text { attendances }\end{array}$ & . & $1: 1 \cdot 2$ & $1: 1 \cdot 4$ & $1: 6 \cdot 5$ & $1: 6 \cdot 1$ \\
\hline
\end{tabular}

Many patients attend for a full day so that comprehensive assessment can be carried out by the unit's staff and consequently the need for inpatient care can often be avoided. Outpatient rehabilitation programmes are arranged to provide a continuing support service to the disabled at home.

\section{Discussion}

The pattern of care adopted by a newly commissioned younger disabled unit has shown that even the most severely disabled individuals may be cared for at home. Substantial benefit can accrue from the close support of a caring family or community. This almost inevitably leads to an increased demand for community support services, but this represents a considerable saving on the cost of hospital-based residential care.

It has been possible to promote this pattern of care largely by taking advantage of the more positive approach to rehabilitation currently practised by the remedial professions. The physiotherapist has increasingly concentrated on restoring or maintaining motor power and locomotor function rather than providing passive or placebo treatments, and the occupational therapist has become skilled in the problems of personal care and environmental adaptations rather than in the supervision of diversional activities. Therapists have also been increasingly collaborating with each other and with their colleagues in the community services. It has therefore been possible to develop a more sensible provision of aids, appliances, and equipment, and to arrange appropriate training in their use.

The increase in co-operation between different groups of health care workers and their increased involvement with local authority social services and housing departments has been to the advantage of the disabled. Only a very small percentage of the young physically disabled population should now be expected to need such a degree of supportive care that they must be provided with long-term residential care on a hospital site.

\section{References}

1 Department of Health and Social Security, HM 6841. London, HMSO, 1968.

${ }^{2}$ Working Group on Strokes, Geriatric Committee, Stroke Disability in Great Britain. London, Royal College of Physicians, 1974.

(Accepted 28 fune 1979)

\title{
Personal Paper
}

\section{Breast or bottle}

\author{
PAULA H BOLTON-MAGGS
}

had little idea about the practicalities. I was surprised to find no interest shown in the method of feeding that I might adopt when I visited GP and hospital clinics. Was this because, knowing me to be a doctor, everybody assumed that I must know it all, or was it because each person assumed that it was somebody else's responsibility? In some areas this important subject may not even be covered in antenatal classes-a DHSS survey ${ }^{1}$ found that $25 \%$ of mothers heard no mention of it. I wonder how uncommitted mothers decide what to do. In the absence of firm advice and encouragement a mother is likely to do what her own mother did or what her peer group does-so that in social classes IV and V especially, where breast-feeding is less common, bottle-feeding will tend to remain the norm.

\section{Finding out}

Apart from the short discussion at one antenatal class my own instruction came entirely from one book, Breast is Best by Penny and Andrew Stanway, which I found invaluable and more useful postnatally than the conflicting advice of midwives and health visitor. I picked up the free literature in the clinics and thought it disappointing. Though the medical profession is learning to accept the sound physiological sense of demand feeding, there still seems a great reluctance to abandon the clock. Also forgotten is the fact that increased suckling produces 